Pacific Journal of Mathematics

THE GIBBS PHENOMENON FOR HAUSDORFF MEANS 


\section{THE GIBBS PHENOMENON FOR HAUSDORFF MEANS}

\section{J. NewmaN}

The existence of a Gibbs phenomenon for the Hausdorff summability method given by $d g(x)[d g$ any measure on $[0,1]$ with total mass 1 and no mass point at 0$]$ is equivalent to the statement

$$
\int_{0}^{1} \int_{0}^{A x} \frac{\sin t}{t} d t d g(x)>\frac{\pi}{2} \text { for some } A>0 .
$$

(See [3])

Recently A. Livingston [1] has treated the case of a $d g$ composed of finitely many mass points and has shown that the Gibbs phenomenon holds under certain additional restrictions. Our result, which follows, contains his and does not require these additional restrictions.

THEOREM 1. Let $d g$ have at least 1 mass point and satisfy $\int_{0}^{1}\left(|d g(x)| / x^{2}\right)<\infty$ then the Gibbs phenomenon occurs for $d g$.

[In particular if $d g$ consists of finitely many mass points, then we have the Gibbs phenomenon].

It seems peculiar that any condition at 0 is necessary, and L. Lorch had even made the conjecture that the Gibbs phenomenon persists for any $d g$ with unbounded Lebesgue constants [and so certainly for any $d g$ with at least one mass point]. Nevertheless we show that some condition at 0 is necessary.

THEOREM 2. There exists a positive $d g$ composed solely of mass points for which the Gibbs phenomenon does not hold.

Thus Lorch's conjecture is definitely false and although our Theorem 1 is by no means best possible it is qualitatively the correct one.

Proof of Theorem 1. We are required to prove that, for a $d g$ satisfying the hypotheses, there is an $A>0$ for which

$$
F(A)=\int_{0}^{1} \int_{A x}^{\infty} \frac{\sin t}{t} d t \quad d g(x) \text { becomes negative. }
$$

This we accomplish by showing that

1.

$$
\int_{1}^{y} F(A) d A \text { remains bounded as } y \rightarrow \infty
$$

2.

$$
F(A) \notin L^{1}(1, \infty) .
$$

Received May 29, 1961. 
Lemma. $\quad F(A)=1 / A \int_{0}^{1}((\cos A x) / x) d g(x)+0\left(1 / A^{2}\right), \quad$ [assuming, of course, that $\left.\int_{0}^{1}(|d g(x)|) / x^{2}<\infty\right]$.

Proof. By two integrations by parts we have

$$
\begin{aligned}
\int_{A x}^{\infty} \frac{\sin t}{t} d t & =\frac{\cos A x}{A x}+\frac{\sin A x}{A^{2} x^{2}}-2 \int_{A x}^{\infty} \frac{\sin t}{t^{3}} d t \\
& =\frac{\cos A x}{A x}+\frac{1}{A^{2} x^{2}}+0\left(\int_{A x}^{\infty} \frac{1}{t^{3}} d t\right) \\
& =\frac{\cos A x}{A x}+0 \frac{1}{A^{2} x^{2}}
\end{aligned}
$$

hence

$$
F(A)=\int_{0}^{1} \frac{\cos A x}{A x} d g(x)+\frac{1}{A^{2}} 0 \int_{0}^{1} \frac{|d g(x)|}{x^{2}}
$$

and the latter integral is finite, by hypothesis.

Proof of 1.

$$
\int_{1}^{y} F(A) d A=\int_{1}^{y} \int_{0}^{1} \frac{\cos A x}{A x} d g(x)+0(1)
$$

by the lemma. Invert the order of integration (this is valid by hypothesis) and we obtain

$$
\begin{aligned}
\int_{1}^{y} F(A) d A & =\int_{0}^{1} \int_{1}^{y} \frac{\cos A x}{A} d A \frac{d g(x)}{x}+0(1) \\
& =\int_{0}^{1} \int_{x}^{x y} \frac{\cos u}{u} d u \frac{d g(x)}{x}+0(1) .
\end{aligned}
$$

But

$$
\int_{x}^{x y} \frac{\cos u}{u} d u=\int_{x}^{1} \frac{\cos u}{u} d u+\int_{1}^{x y} \frac{\cos u}{u} d u
$$

$0 \log 1 / x+0(1)$ since $\int_{1}^{\infty}((\cos u) / u) d u$ converges. Finally then

$$
\int_{1}^{y} F(A) d A=\int_{0}^{1} \log \frac{1}{x} \frac{|d g(x)|}{x}+0(1)=0(1) .
$$

Proof of 2. Again by the lemma,

$$
F(A)=\frac{1}{A} \int_{0}^{1} \cos A x \frac{d g(x)}{x}+0 \frac{1}{A^{2}} .
$$


Now call

$$
\int_{0}^{1} \cos A x \frac{d g(x)}{x}=G(A)
$$

If we split the measure $(d g(x)) / x$ into its continuous part and its mass points, then we split $G(A)$ into $h(A)+j(A)$ where $j(A)$ is almost periodic. It is shown by Lorch and Newman [2] that

$$
\frac{1}{T} \int_{0}^{T}|h(A)| d A \rightarrow 0
$$

while, of course,

$$
\frac{1}{T} \int_{0}^{T}|j(A)| d A \rightarrow M>0,
$$

$M$ denoting the mean value of the positive almost periodic function $|j(A)|$. Hence $1 / T \int_{1}^{T}|G(A)| d A \rightarrow M$. Integration by parts gives that $1 /(\log T) \int_{1}^{T}(|G(A)| \mid A) d A \rightarrow M$ and so, since

$$
\int_{1}^{T^{\prime}}\left|F^{\prime}(A)\right| d A=\int_{1}^{t^{\prime}} \frac{|G(A)|}{A} d A \mid 0(1)
$$

we find that

$$
\int_{1}^{T^{\prime}}|F(A)| d A \sim M \log T
$$

and $F(A) \notin L_{1}(1, \infty)$. The proof is complete.

Proof of Theorem 2. Call $\phi(x)=\int_{x}^{\infty}((\sin t) / t) d t$. We will find a sequence of $\alpha_{n}$ in $(0,1)$ such that $\sum_{n=1}^{\infty}\left(1 / 2^{n}\right) \phi\left(\alpha_{n} A\right) \geqq 0$ for all $A \geqq 0$. This being so, the choice of $d g$ with the masses $1 / 2^{n}$ at the points $\alpha_{n}$ will satisfy our requirements.

We will choose the $\alpha_{n}$ inductively so that $\sum_{n=1}^{N}\left(1 / 2^{n}\right) \phi\left(\alpha_{n} A\right) \geqq-1 / 2^{N}$ for all $A$. Clearly the choice $\alpha_{1}=1$ satisfies this requirement when $N=1$. Suppose that $\alpha_{1}, \alpha_{2}, \cdots, \alpha_{N}$ have been chosen so that this requirement is satisfied. Since $\phi(\infty)=0$ we can determine $A_{0}$ such that $A \geqq A_{0}$ insures $\sum_{n=1}^{N}\left(1 / 2^{n}\right) \phi\left(\alpha_{n} A\right) \geqq-1 / 2^{N+2}$. Also since $\phi(0)=\pi / 2$ we can determine an $\alpha>0$ so small that $\phi(\alpha A) \geqq 1$ for $A \leqq A_{0}$. The claim is that this serves as our $\alpha_{N+1}$.

We have

$$
\sum_{n=1}^{N+1} \frac{1}{2^{n}} \phi\left(\alpha_{n} A\right)=\sum_{n=1}^{N} \frac{1}{2^{n}} \phi\left(\alpha_{n} A\right)+\frac{\phi(\alpha A)}{2^{N+1}}
$$




$$
\geqq-\frac{1}{2^{N}}+\frac{1}{2^{N+1}}+-\frac{1}{2^{N+1}} \text { for } A \leqq A_{0}
$$

while, since $\phi(x) \geqq-1 / 2$ always, we obtain

$$
\sum_{n=1}^{N} \frac{1}{2^{n}} \phi\left(\alpha_{n} A\right)+\frac{\phi(\alpha A)}{2^{N+1}} \geqq-\frac{1}{2^{N+2}}+\frac{-1 / 2}{2^{N+1}}=-\frac{1}{2^{N+1}}
$$

for $A \geqq A_{0}$. The construction of the $\alpha_{n}$ completes the proof.

It is interesting to note that the above construction, when carried out carefully, leads to a $d g$ satisfying $\int|d g(x)| / x^{1 / 2}<\infty$, so that our Theorem 1 is false when the exponent 2 is replaced by $1 / 2$. It would be interesting to find the correct exponent.

We wish to thank L. Lorch and A. Shields for their useful suggestions in regard to the above results.

\section{REFERENCES}

1. A. Livingston, Some Hausdorff means which exhibit the Cibbs' Phenomenon, Pacific J. Math., 3 (1953), 407-415.

2. L. Lorch and D. J. Newman, The Lebesgue constants for regular Hausdorff methods, Canadian J. Math., 13 (1961), 288.

3. O. Szasz, Gibbs' phenomenon for Hausdorff means, Trans. Amer. Math. Soc., 69 (1950), 440-456.

YESHIVA UNIVERSITY 


\section{PACIFIC JOURNAL OF MATHEMATICS}

\section{EDITORS}

Ralph S. Phillips

Stanford University

Stanford, California

M. G. Arsove

University of Washington

Seattle 5, Washington
A. L. Whiteman

University of Southern Californla

Los Angeles 7, California

Lowell J. Paige

University of California

Los Angeles 24, California

\section{ASSOCIATE EDITORS}

E. F. BECKENBACH

D. DERRY

H. L. ROYDEN

E. G. STRAUS

T. M. CHERRY

M. OHTSUKA

E. SPANIER

F. WOLF

\section{SUPPORTING INSTITUTIONS}

UNIVERSITY OF BRITISH COLUMBIA

STANFORD UNIVERSITY

CALIFORNIA INSTITUTE OF TECHNOLOGY

UNIVERSITY OF CALIFORNIA

MONTANA STATE UNIVERSITY

UNIVERSITY OF TOKYO

UNIVERSITY OF UTAH

UNIVERSITY OF NEVADA

NEW MEXICO STATE UNIVERSITY

OREGON STATE UNIVERSITY

UNIVERSITY OF OREGON

OSAKA UNIVERSITY

WASHINGTON STATE UNIVERSITY

UNIVERSITY OF WASHINGTON

UNIVERSITY OF SOUTHERN CALIFORNIA

AMERICAN MATHEMATICAL SOCIETY CALIFORNIA RESEARCH CORPORATION SPACE TECHNOLOGY LABORATORIES NAVAL ORDNANCE TEST STATION 


\section{Pacific Journal of Mathematics}

\section{Vol. 12, No. $1 \quad$ January, 1962}

Jonathan L. Alperin, Groups with finitely many automorphisms $\ldots \ldots \ldots \ldots \ldots \ldots \ldots \ldots$

Martin Arthur Arkowitz, The generalized Whitehead product ................ 7

John D. Baum, Instability and asymptoticity in toplogical dynamics . . . . . . . . . . 25

William Aaron Beyer, Hausdorff dimension of level sets of some Rademacher series .... $\quad 35$

Frank Herbert Brownell, III, A note on Cook's wave-matrix theorem . . . . . . . . . . . . . 47

Gulbank D. Chakerian, An inequality for closed space curves ................. 53

Inge Futtrup Christensen, Some further extensions of a theorem of Marcinkiewicz ....... 59

Charles Vernon Coffman, Linear differential equations on cones in Banach spaces . . . . . 69

Eckford Cohen, Arithmetical notes. III. Certain equally distributed sets of integers . . . . . 77

John Irving Derr and Angus E. Taylor, Operators of meromorphic type with multiple poles

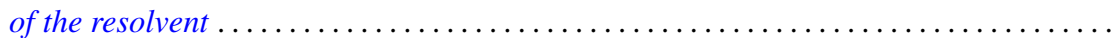

Jacob Feldman, On measurability of stochastic processes in products space .............

Robert S. Freeman, Closed extensions of the Laplace operator determined by a general class of boundary conditions, for unbounded regions ......................

Robert E. Fullerton, Geometric structure of absolute basis systems in a linear topological

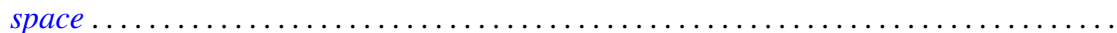

Dieter Gaier, On conformal mapping of nearly circular regions

Andrew Mattei Gleason and Hassler Whitney, The extension of linear functionals defined

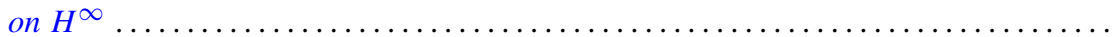

Seymour Goldberg, Closed linear operators and associated continuous linear

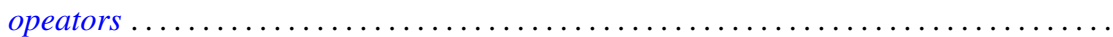

Basil Gordon, Aviezri Siegmund Fraenkel and Ernst Gabor Straus, On the determination of sets by the sets of sums of a certain order

Branko Grünbaum, The dimension of intersections of convex sets. .

Paul Daniel Hill, On the number of pure subgroups

Robert Peter Holten, Generalized Goursat problem . .

Alfred Horn, Eigenvalues of sums of Hermitian matrices ...........

Henry C. Howard, Oscillation and nonoscillation criteria for

$$
y^{\prime \prime}(x)+f(y(x)) p(x)=0
$$

Taqdir Husain, $S$-spaces and the open mapping theorem ...

Richard Eugene Isaac, Markov processes and unique stationary probability measures ...

John Rolfe Isbell, Supercomplete spaces ....................

John Rolfe Isbell, On finite-dimensional uniform spaces. II .........

N. Jacobson, A note on automorphisms of Lie algebras ..............

Antoni A. Kosinski, A theorem on families of acyclic sets and its applications

Marvin David Marcus and H. Minc, The invariance of symmetric functions of singular values...

Ralph David McWilliams, A note on weak sequential convergence.

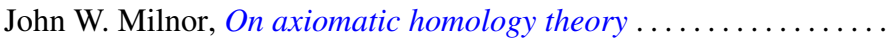

Victor Julius Mizel and Malempati Madhusudana Rao, Nonsymmetric projections in

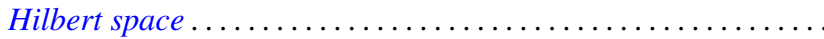

Calvin Cooper Moore, On the Frobenius reciprocity theorem for locally compact

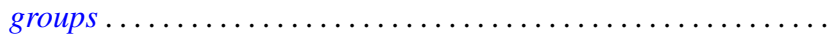

Donald J. Newman, The Gibbs phenomenon for Hausdorff means . 